\title{
Florida's Aquifer Vulnerability to Nitrate Contamination: A GIS Model
}

\author{
M. Jamuna*†, M. Gandhimathi*, J. Abdul Bari** and T. Niveditha*** \\ *Department of Civil Engineering, Kumaraguru College of Technology, Coimbatore, India \\ **Department of Civil Engineering, K.S. Rangasamy College of Technology, Tiruchengode, India \\ ***Department of Environmental Engineering, Florida University, USA \\ $\dagger$ Corresponding author: M. Jamuna; jamuna.m.ce@kct.ac.in
}

Nat. Env. \& Poll. Tech.

Website: www.neptjournal.com

Received: 17-04-2021

Revised: 12-05-2021

Accepted: 25-05-2021

Key Words:

Groundwater

Nitrogen contamination

GIS techniques

Kriging interpolation

DRASTIC model

Thematic map

\section{ABSTRACT}

Groundwater is a crucial natural resource in the state of Florida. since it supports to environmental, social, and economic aspects of the country. Groundwater will not be contaminated easily but it is difficult to restore once it is contaminated. Since its extensive usage in agricultural activities in the state of Florida, groundwater has degraded in recent years, resulting in many direct and indirect impacts, particularly nitrogen content in the form of nitrates using Geographical Information System (GIS) technology, the researchers investigated the effects of groundwater on Nitrogen $\left(\mathrm{NO}_{3}\right)$ content in the study area by creating a spatial distribution of $\mathrm{NO}_{3}$ contamination, which was then analyzed using GIS, Kriging Interpolation, and the DRASTIC model to determine the susceptibility of groundwater to $\mathrm{NO}_{3}$ contamination. The final result depicts the model's performance as vulnerability groups, which are based on natural breaks showing places that are more susceptible to nitrogen pollution. The map highlighted that the south zone of Florida was more vulnerable to nitrogen contamination, necessitating more careful wastewater disposal system planning.

\section{INTRODUCTION}

The importance of water in human life and culture cannot be overstated. Both groundwater and surface water play important roles in economic, social, health, recreational, and cultural activities, as well as in environmental and ecosystem preservation (Abdul Bari et al. 2015, Tirkey et al. 2013, Anornu et al. 2012). Although water covers 70 per cent of the Earth, groundwater accounts for just 0.6 per cent of all usable water; however, that 0.6 per cent accounts for 98 per cent of all freshwater available for human use. Water found in soil and rock pore spaces underneath the Earth's crust, as well as in the cracks of rock formations, is known as groundwater, while water found above the ground is known as surface water. Because of rapid population growth, surface water volume and quality are dwindling, leaving groundwater as the most reliable source of water in terms of quality. The most critical water resource on the planet is groundwater (Abdul Bari \& Jamuna 2020). It is the sole source of water for drinking, agriculture, and industrial uses in many arid and semi-arid areas around the world (Tesoriero et al. 1998). Residential, municipal, commercial, manufacturing, and agricultural activities can all affect groundwater quality, particularly when it comes to fertilizer overuse and unsanitary conditions (Tesoriero et al. 1998). Fertilizers contain nitrogen compounds which increase the productivity of crops. The increasing demand for nitrogen disposal regulation in recent years prompted the selection of this topic for research. The problem of nitrate leaching in the surface and groundwater has been studied in recent years. Excess Nitrogen has harmed nearly 4,800 water bodies in the United States (U.S. EPA 2012). Septic systems are recognized as one of the major sources of Nitrogen pollution. The rising nutrient content in treated sewage is posing a threat to the ecosystem by causing many environmental issues such as eutrophication (example: summer algal blooms). The high level of $\mathrm{NO}_{3}$ in the water affects the health of human beings and causes methemoglobinemia called Blue Baby Syndrome, Birth Malformation, and other issues. Nitrate concentrations in drinking water exceeding 10 milligrams per liter $\left(10 \mathrm{mg} . \mathrm{L}^{-1}\right)$ can be dangerous if consumed, according to US Environmental Protection Agency (EPA) guidelines (EPA 2009). Several studies have used different approaches to determine the susceptibility of groundwater to nitrate pollution and other contaminants. These techniques can be classified as follows: Overlay and Index Methods, Process-Based Methods, and Statistical Methods (Tesoriero et al. 1998, Thirumalaivasan \& Venugopal 2003), out of which the DRASTIC model, which comes under the Overlay and Index group, is one of the most commonly used groundwater vulnerability mapping methods. DRASTIC is an acronym that stands for Depth to water, net Recharge, Aquifer media, Soil media, Topography, 
Impact of the vadose zone. and hydraulic Conductivity (Aller et al. 1987). The purpose of this study is to explore nitrogen's existence and transportation to find and recognize areas in Florida that are more vulnerable to pollution. The ultimate goal of this research work is to use GIS-based modeling to create a model that can identify areas that are most susceptible to nitrogen pollution.

\section{STUDY AREA}

The state of Florida was chosen because of its exceptional hydrogeological features. The most striking conclusion that historical research conveys about Florida and its ecosystems is that in any one area there have been immense changes (Webb 1990).

Florida is a living example of S.D. Webb's terms. It incorporates hydrogeological history (from shallow waterfronts to aquifers), climatic conditions, geography, and environmental forces in a specific way. These characteristics have resulted in Florida being a vast repository of landscape, plant population, and species diversity, which supports significant ecological, taxonomic, and genetic diversity. Because of these distinguishing characteristics, spatial differences in Florida's groundwater are susceptible to nitrogen contamination from onsite wastewater treatment facilities. Exposure to oceanic waters has a major impact on the state's climatic conditions. This is particularly apparent when it comes to temperature and rainfall. The temperature is warm, the rain is heavy, and the humidity is high. With an average daily temperature of $70.7^{\circ} \mathrm{F}\left(21.5^{\circ} \mathrm{C}\right)$, Florida is the warmest state in the United States. In July, average high temperatures range from $90^{\circ} \mathrm{F}\left(32.2^{\circ} \mathrm{C}\right)$ to $95^{\circ} \mathrm{F}\left(35^{\circ} \mathrm{C}\right)$, while average low temperatures in January range from $40^{\circ} \mathrm{F}\left(4.4^{\circ} \mathrm{C}\right)$ to $45^{\circ} \mathrm{F}$ $\left(7.2^{\circ} \mathrm{C}\right)$ in the northern part of the state and $60^{\circ} \mathrm{F}\left(15.6^{\circ} \mathrm{C}\right)$ to $65^{\circ} \mathrm{F}\left(18.3^{\circ} \mathrm{C}\right)$ in the southern part. The great majority of the state is located within a region with annual rainfall ranging from 48 to 57 inches. The average annual rainfall for the entire state is about 54 inches. Rainfall occurs in irregular patterns during the year.

\section{MATERIALS AND METHODS}

The main aim of this project is to create a thematic map for Florida that portrays the areas most susceptible to nitrogen pollution. Using the Soil Data Viewer method in ArcGIS, this can be achieved spatially. When used independently of ArcGIS, this tool allows users to create soil-based thematic maps or generate a tabular report. Soil Data Viewer could be used to access soil properties and interpretations after shielding them from the soil database's complexity. The methodology used for this investigation is shown in Fig. 1 (United States Department of Agriculture 2015).

\section{Method of Research Focused on GIS}

Since the 1980s, GIS has been successfully used to determine the susceptibility of groundwater to pollution (Al-Adamat et al. 2003, Vias et al. 2005, Baalousha 2006, Jamrah et al. 2007, Sener et al. 2009, Massone et al. 2010). For groundwater analyses, several recent studies have used interpolation approaches, the most popular of which are Inverse Distance Weighting (IDW) and kriging. In situations where there is little or no groundwater monitoring data, researchers have used a different approach, in which a vulnerability model is first established using site-specific geological data. and then field-tested using either current or specially acquired groundwater data (Margat 1968). Since then, several vulnerability mapping methods have appeared, including CMLS (Nofziger \& Hornsby 1986, 1987), DRASTIC (Aller et al. 1987), GOD (Foster 1987), LEACHM (Wagenet \& Hutson 1989), AVI (Van Stempvoort et al. 1993), and SINTACS (Van Stempvoort et al. 1993, Ersoy \& Gultekin 2013).

\section{DRASTIC Model}

Several studies have used the DRASTIC model to determine groundwater and aquifer risk in different parts of the world. The model generates regional maps that demarcate areas of low, moderate, and high vulnerability, which could be followed up with additional site-specific analysis. The use of the DRASTIC index model to evaluate the study area's groundwater vulnerability has been meticulously investigated. The application procedure was given in Table 1.

The DRASTIC index is calculated using Equation

DRASTIC index $=\mathrm{DrDw}+\mathrm{RrRw}+\mathrm{ArAw}+\mathrm{SrSw}+\mathrm{TrTw}$ $+\mathrm{IrIw}+\mathrm{CrCw}$

Where D, R, A, S, T, I, and C are the seven parameters

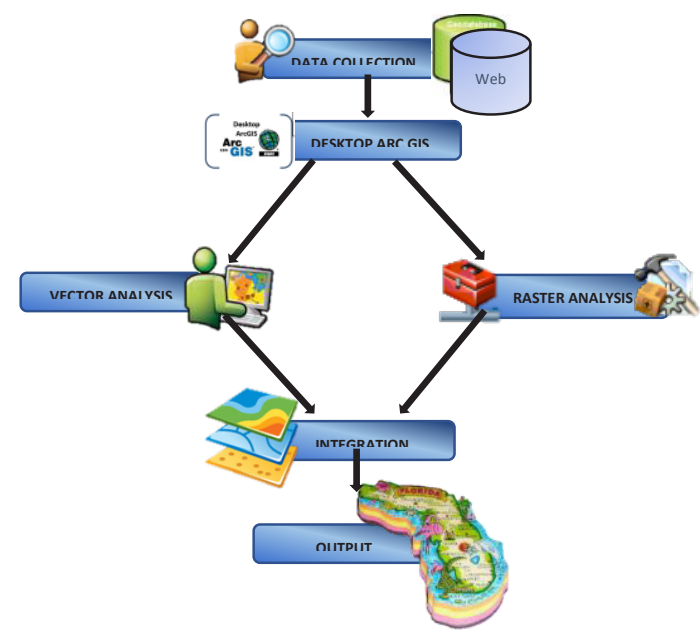

Fig. 1: Methodology. 
described subscript $r$ is the corresponding rating of the parameter, and subscript $\mathrm{w}$ is the corresponding weights of the parameters.

Where,

$\mathrm{Dr}=$ Ratings to the depth to the water table

Dw $=$ Weight assigned to the depth to the water table

$\mathrm{Rr}=$ Ratings for ranges of aquifer recharge

$\mathrm{Rw}=$ Weight for aquifer recharge

$\mathrm{Ar}=$ Ratings assigned to aquifer media

Aw $=$ Weight assigned to aquifer media

$\mathrm{Sr}=$ Ratings for soil media

$\mathrm{Sw}=$ Weight for soil media

$\mathrm{Tr}=$ Ratings for topography

$\mathrm{Tw}=$ Weight assigned to topography

$\mathrm{Ir}=$ Ratings assigned to vadose zone

Iw $=$ Weight assigned to vadose zone

$\mathrm{Cr}=$ Ratings for rates of hydraulic conductivity

$\mathrm{Cw}=$ Weight given to hydraulic conductivity

A Geographic Information System (GIS) was also used in the DRASTIC model to visualize the areas of Florida that are most vulnerable to nitrogen contamination (Arthur et al. 2007). The most limitation of this approach is that all seven parameters are rated on a specific scale in some order, preventing continuous data from being considered. Fig. 2 Shows the DRASTIC vulnerability map.

\section{FAVA Model}

Florida's Department of Environmental Protection created a descendant model, the Florida Aquifer Vulnerability Assessment (FAVA). FAVA employs the Weight of Evidence (WOE) model to make predictions based on nitrate concentrations in wells and other spatial data, which are then shown as vulnerability maps.

The FAVA model made use of training points, which are places where prior likelihood and spatial data results are known. The training points in this case were wells with total dissolved nitrogen samples that were less than the median value. The data is weighted and evidential maps are built based on areas that have a strong resemblance to the training point areas. Several of these maps are combined in GIS to make response maps which are used to generate

Table 1: The pollution potential conditioning factors (PPCFs) ratings and their weights (Chen et al. 2009).

\begin{tabular}{|c|c|c|c|}
\hline Criteria & Ranges & $\begin{array}{l}\text { Pollution Potentiality for groundwater } \\
\text { vulnerability }\end{array}$ & Weight Assigned \\
\hline \multirow[t]{3}{*}{ Depth to water (D) } & $0.34-1.58$ & High & 5 \\
\hline & $1.86-2.14$ & Medium & 4 \\
\hline & $2.14-2.53$ & Low & 3 \\
\hline \multirow[t]{3}{*}{ Recharge Rate (R) } & $228.68-243.33$ & Low & 1 \\
\hline & $243.33-256.56$ & Medium & 2 \\
\hline & $256.56-278.77$ & High & 5 \\
\hline \multirow[t]{3}{*}{ Aquifer Media (A) } & $250-305 \Omega$ & Medium & 3 \\
\hline & $367-445 \Omega$ & Low & 2 \\
\hline & $445-600 \Omega$ & High & 5 \\
\hline \multirow[t]{3}{*}{ Soil Media (S) } & Igneous Rocks & Low & 2 \\
\hline & Sedimentary Rocks & Medium & 3 \\
\hline & Low Humic Gley soil developed in the valley and flood plain & High & 5 \\
\hline \multirow[t]{3}{*}{ Topography (T) } & $0-2.57$ & High & 4 \\
\hline & $8.77-15.54$ & Medium & 3 \\
\hline & $15.54-25.83$ & Low & 2 \\
\hline \multirow{3}{*}{$\begin{array}{l}\text { Impact of Vadose } \\
\text { Zone(I) }\end{array}$} & $388-511 \Omega$ & High & 5 \\
\hline & $511-793 \Omega$ & Medium & 3 \\
\hline & 793- $1464 \Omega$ & Low & 2 \\
\hline \multirow{3}{*}{$\begin{array}{l}\text { Hydraulic conduc- } \\
\text { tivity (C) }\end{array}$} & 0.0018- 0.0034 & Low & 2 \\
\hline & $0.0034-0.0069$ & Medium & 3 \\
\hline & $0.00127-0.0270$ & High & 5 \\
\hline
\end{tabular}


the probability map displaying aquifer vulnerability to nitrogen.

The main change that would be implemented in this model is that it includes details considering human sources of contamination from OWTS and also it considers the areas other than SAS (Surficial Aquifer System) region.

The maps of the DRASTIC (Fig. 2) and FAVA (Fig. 3) model show that the SAS region of Florida has not been considered in the study. The contaminant removal equation also involves parameters including reaction rates and retardation factors. This method would assess Nitrogen risk for the entire state of Florida by looking at contaminant fate and transport processes for nitrate.

\section{Fate and Transport Equation}

The advection-disper' 1 sion equation in $\mathrm{N}$-calc (McCray et al. 2005) was used to calculate nitrogen removal in the vadose region. It's simplified by ignoring dispersion's effects and assuming steady-state conditions.

The elementary equation for contaminant removal is an exponential decay function,

$$
\mathrm{C}(\mathrm{z})=\mathrm{C}_{0} \exp \left(\frac{-\mathrm{RK}_{\mathrm{r}}}{\mathrm{v}_{\mathrm{z}}} \mathrm{Z}\right)
$$

Where,

$\mathrm{C}(\mathrm{z})$ is the ultimate measuring point (i.e.) the amount of Nitrogen concentration left in the water table

$\mathrm{C}_{0}$ is the initial concentration of ammonium or nitrate (mg.L $\mathrm{L}^{-1}$ )

$\mathrm{R}$ is retardation factor

$\mathrm{K}_{\mathrm{r}}$ is the first-order reaction rate

$\mathrm{V}_{\mathrm{z}}$ is the vertical water velocity $\left(\mathrm{cm}^{\mathrm{day}}{ }^{-1}\right.$ )

$\mathrm{Z}$ is the soil depth $(\mathrm{cm})$

This can be used to calculate the concentration of

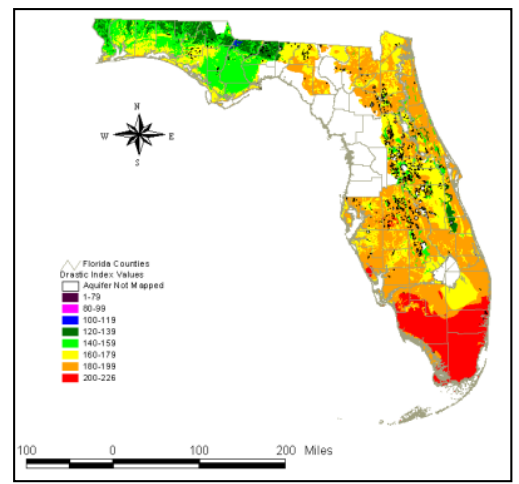

Fig. 2: DRASTIC vulnerability map for the Surficial Aquifer System. ammonium and nitrate as a function of the removal processes.

- The initial concentration, $\mathrm{C}_{0}$ can be obtained from the source of contamination, OWTS (Onsite Wastewater Treatment Systems)

- The retardation factor, $\mathrm{R}$ is got from various soil properties like distribution coefficient, bulk density, soil moisture content.

$$
\mathrm{R}=1+\frac{\mathrm{K}_{\mathrm{d}}}{\theta} \rho
$$

Where,

$\mathrm{Kd}$ is the distribution coefficient $\left({\left.\mathrm{L} . \mathrm{kg}^{-1}\right)}^{-1}\right.$

$\theta$ is the soil moisture content (\%)

$\rho$ is the bulk density of the soil $\left(\mathrm{g} . \mathrm{cm}^{-3}\right)$

- $\mathrm{K}_{\mathrm{r}}$ is the first-order reaction rate, that can be attained from the cumulative frequency diagram (CFD) of reaction rates (McCray et al. 2005)

- Depth of water table is obtained from Web soil survey by USDA.

The model input parameters that are included in this model are

- The initial concentration of ammonium or nitrate

- Distribution coefficient

- Soil moisture content

- Bulk density of the soil

- First-order reaction rate

- Depth to the water table

\section{The Initial Concentration of Ammonium or Nitrate}

The primary source of nitrogen disposal is onsite wastewater treatment facilities (Fig. 4). The Florida Department of Health maintains a list of OWTS locations in the state. The

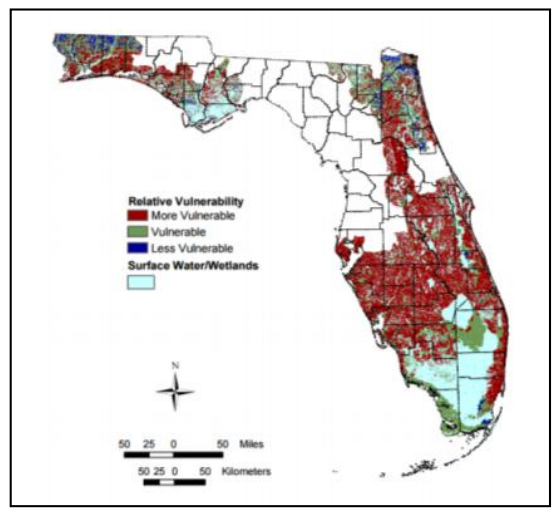

Fig. 3: Florida Aquifer Vulnerability Assessment (FAVA) response theme. 
nitrogen content in the effluent disposed of is $60 \mathrm{mg} . \mathrm{L}^{-1}$, which is the median concentration.

\section{Depth to the Water Table}

- The depth to groundwater for the Model was collected from the National Water Information System of the United States Geological Survey (NWIS). The NWIS database provides information on active good networks, as well as statistics on groundwater levels. The GA tool in ArcMap was then used to construct a continuous projected depth water table surface (using ordinary kriging interpolation), which was then translated into a raster file for further analysis. The map was categorized into ranges identified by the DRASTIC Model after the IDW (1-10, with 1 representing minimal impact to vulnerability and 10 representing maximum impact). The lower the ranking score, the deeper the groundwater. The depth to water map is given in Fig. 5. Depth to the water table is one of the major factors affecting contaminant transformation.

- The term $\left(\mathrm{z} / \mathrm{v}_{\mathrm{z}}\right)$ from the equation is taken as Depth to the water table.

- This is also obtained using the Soil Development Tool, which gives the annual minimum water table depth in centimeters. The water table depth ranged from 0 to 201 $\mathrm{cm}$ throughout the area of Florida.

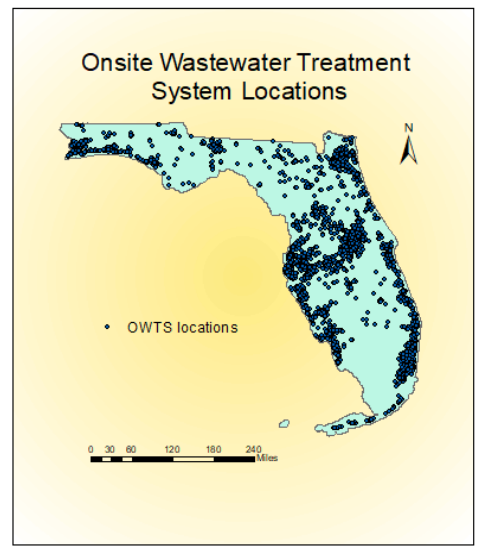

Fig. 4: The point locations of OWTS.

\section{Retardation Factor}

The retardation factor, $\mathrm{R}$ is got from

$$
\mathrm{R}=1+\frac{\mathrm{K}_{\mathrm{d}}}{\theta} \rho
$$

A new field showing the Kd value based on clay content is generated.

Soil moisture content and bulk density are obtained from USDA soil literature (Table 2) based on soil texture. Soil texture data is also available from the Soil Development Tool and two new fields are added as soil moisture content and bulk density. The soil moisture content is assumed to be porosity. The values of bulk density and porosity are obtained from Table 3 and are added manually to the new fields based on the soil texture. With these obtained values, a new field is created with all the factors substituted and hence Retardation Factor is obtained (Fig. 6). The Retardation Factor value ranges from 1.17 to 5.30. A symbology map showing the variation is generated as shown.

\section{RESULTS AND DISCUSSION}

The various layers were generated based on the above section using the databases listed in data sources and the Soil data viewer tool. The soil texture thematic map was created as shown in Fig. 7.

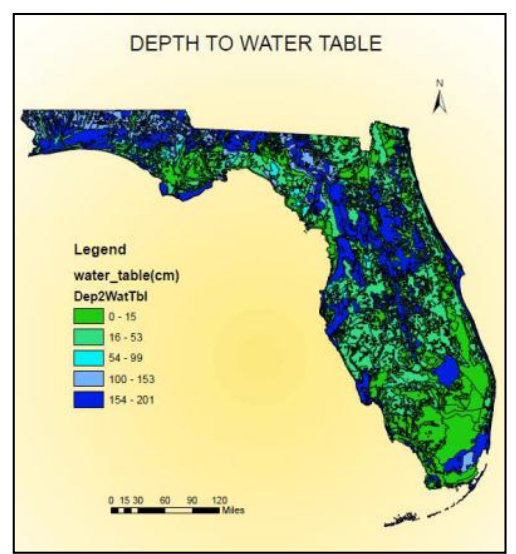

Fig. 5: Depth to water table for the State of Florida.

Table 2: Data sources of parameter values and spatial data used in the study.

\begin{tabular}{|lll|}
\hline Name & Source & Description \\
\hline Web Soil Survey Geographic database & U.S. Department of Agriculture (USDA) & Soil data \\
Wastewater inventory database & Florida Department of Health & Florida Water Management Inventory \\
Porosity & Rawls et al. 1982 & Porosity values for USDA soil textures \\
\hline
\end{tabular}


As a result, 18 soil layers were formed, one of which was a variable field into which the sample mean values were fed. The Retardation factor map was created after the parameters for the Retardation factor were obtained. The range of retardation factors corresponded to the theoretical range for Florida. It was in the range of 1.16 to 5.3. (no unit). After the individual layers, the final map depicting the remaining Nitrate concentration is produced which is shown in Fig. 8

The residual nitrate concentration varied between less than $1 \mathrm{mg} . \mathrm{L}^{-1}$ and $60 \mathrm{mg} . \mathrm{L}^{-1}$. The higher concentration zones are caused by shallow depth to aquifer values and/or low $\mathrm{Kr}$ concentrations, which prevent complete ammonium to nitrate conversion. From Fig. 5, it is evident that most of the area is prone to contamination owing to the fact that the annual Depth to the water table in Florida is generally shallow, ranging from $0 \mathrm{~cm}$ to $201 \mathrm{~cm}$ with about $25 \%$ of the area $\leq 5 \mathrm{~cm}$. In addition, the more susceptible areas of

Table 3: Porosity classified by soil texture. (Rawls et al. 1982)

\begin{tabular}{|lll|}
\hline USDA Soil Texture & Sample Size & $\begin{array}{l}\text { Total Porosity/Satura- } \\
\text { tion } \Theta \mathrm{s}\left[\mathrm{cm}^{3} \cdot \mathrm{cm}^{-3}\right]\end{array}$ \\
\hline Sand & 762 & 0.437 \\
Loamy sand & 338 & 0.437 \\
Sandy loam & 666 & 0.453 \\
Loam & 383 & 0.463 \\
Silt loam & 1206 & 0.501 \\
Sandy clay loam & 498 & 0.398 \\
Clay loam & 366 & 0.464 \\
Silty clay loam & 689 & 0.471 \\
Sandy clay & 45 & 0.430 \\
Silty clay & 127 & 0.479 \\
Clay & 291 & 0.475 \\
\hline
\end{tabular}

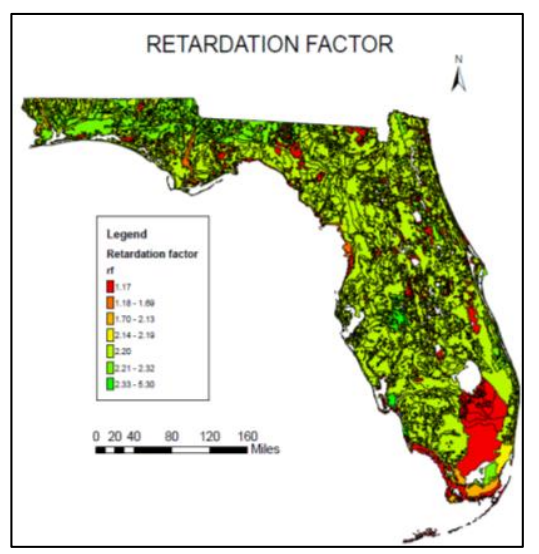

Fig. 6: Retardation Factor layer for the state of Florida.
Florida share the same limestone layers and wetlands found in the southern part of the state. The areas within the gravel and sand aquifer are also less vulnerable.

\section{CONCLUSION}

The map's findings show that the most vulnerable areas have a shallow depth to water table measurements, as can be seen on the depth to water table map (Fig. 5) and the remaining nitrate content map (Fig. 8). This would improve wastewater laws to a greater degree. If the appropriate equation and parameters are available, the same modeling technique can be established for any contaminant in any given field.

\section{REFERENCES}

Abdul Bari, J., Vennila, G. and Shanmugaraja, T.M. 2015. Physico-chemical characteristics of groundwater of Bhavani block, Erode District, Tamilnadu, India Rasayan J. of Chem., 8(2): 198 -202.

Abdul Bari, J. and Jamuna, M. 2020. Assessment of hydrogeochemistry and evaluation of groundwater quality feasibility zones in Bhavani Taluk, Tamilnadu, India. Int. J. of Adv. Sci. Tech., 29(7): 8323-8333.

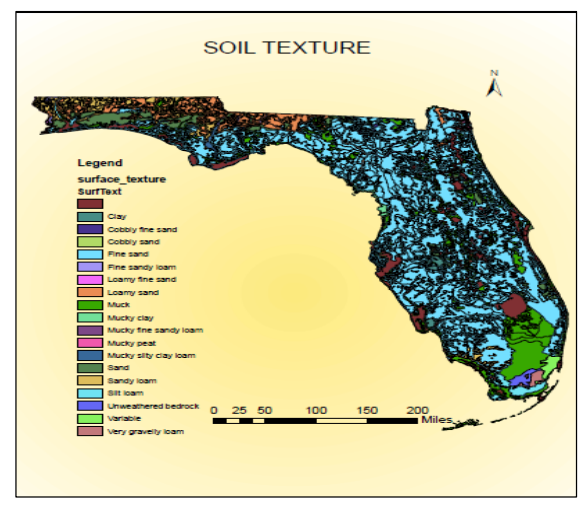

Fig. 7: Soil texture layer for the state of Florida.

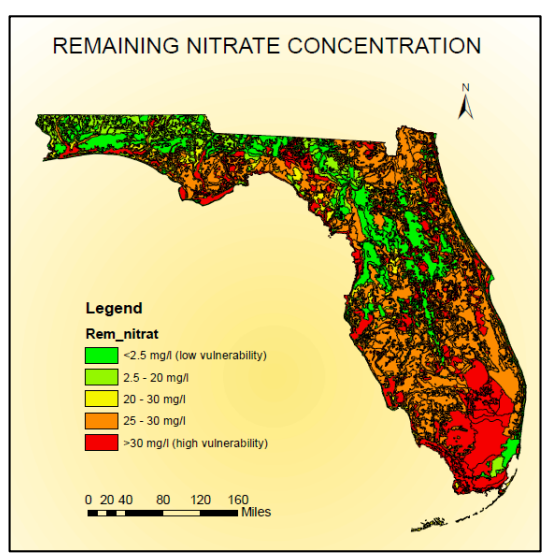

Fig. 8: Florida nitrogen vulnerability map. 
Al-Adamat, R., Ian, L.F. and Serwan, M.J. B. 2003. Groundwater vulnerability and risk mapping for the basaltic aquifer of the Azraq Basin of Jordan using GIS, Remote Sensing, and DRASTIC. Appl. Geog., 23(4): 303-324.

Aller, L., Todd, B., Jay, H.L. and Richard, J.P. 1987. DRASTIC: A Standardized System for Evaluating Ground Water Pollution Potential Using Hydrogeologic Settings. EPA/600/2-85/018, US Environmental Protection Agency, Robert S. Kerr Environmental Research Laboratory, Office of Research and Development.

Anornu, G.K., Kabo-bah, A.T. and Anim-Gyampo, M. 2012. Evaluation of groundwater vulnerability in the Densu River basin of Ghana. Amer. J. of Human Ecol., 1(3): 79-86.

Arthur, J. D., Wood, H. A. R., Baker, A. E., Cichon, J. R. and Raines, G. L. 2007 Development and implementation of a Bayesian based aquifer vulnerability assessment in Florida, Natural Resources Research, 16: 93-107.

Baalousha, H. 2006. Vulnerability assessment for the Gaza Strip, Palestine using DRASTIC. Environ. Geol., 50: 405-414.

Chen, Y., Khan, S. and Paydar, Z. 20010. To retire or expand? A fuzzy GIS-based spatial multi-criteria evaluation framework for irrigated agriculture. Irrig. Drain., 59(2): 174-188.

Ersoy, A.F. and Gultekin, F. 2013. DRASTIC-based methodology for assessing groundwater vulnerability in the Gumushacikoy and Merzifon Basin (Amasya, Turkey). Earth Sci. Res. J., 17(1): 33-40.

EPA 2009. National Primary Drinking Water Regulations, U.S. Environmental Protection Agency Report 816-F-09-004.

Foster, S. 1987. Fundamental Concepts in Aquifer Vulnerability, Pollution Risk and Protection Strategy." The Netherlands Vulnerability of Soil and Groundwater to Pollutants The Hague. Noordwijk Aan Zee: Netherlands Organization for Applied Scientific Research., pp. 69-86.

Jamrah, A., Al-Futaisi, A. and Rajmohan, N. 2008. Assessment of groundwater vulnerability in the coastal region of Oman using DRASTIC index method in GIS environment. Environ. Monit. Assess., 147: 125-138.

McCray, J.E., S.L Kirkland., R.L. Siegrist, and G.D. Thyne 2005. Model Parameters for Simulating Fate and Transport of On-Site Wastewater Nutrients. Ground Water, 43(4): 628-639.

Massone, H., Mauricio, Q.L. and Daniel, M. 2010. Enhanced groundwater vulnerability assessment in geological homogeneous areas: A case study from the Argentine Pampas. Hydrogeol. J., 23: 371-379.

Margat, J. 1968. Groundwater Vulnerability to Contamination. Doc, Orleans,
France: 68 SGC 198 HYD, BRGM.

Nofziger, D.L. and Hornsby, A.G. 1986. A microcomputer-based management tool for chemical movement in the soil. Appl. Agric. Res., 1: 50-56.

Nofziger, D. L. and Hornsby, A.G. 1987. CMLS: Chemical Movement through Layered Soils Model Users Manual. Gainesville, FL: University of Florida.

Rawls, W. J., D. L. Brakensiek, and K. E. Saxton. 1982. Estimationof soil water properties. Trans. ASAE 25(5): 1316-1320

Sener, E., Sehnaz, S. and Aysen, D. 2009. Assessment of aquifer vulnerability based on GIS and DRASTIC methods: A Case Study of the Senirkent-Uluborlu Basin (Isparta, Turkey). Hydrogeology Journal 2023-2035.

Tirkey, P., Gorai, A.K. and Iqbal, J. 2013. AHPGIS-based DRASTIC model for groundwater vulnerability to pollution assessment: A case study of Hazaribag district, Jharkhand, India. International Journal of Environmental Protection., 3(9): 20-24

Tesoriero, A.J., Inkpen, E.L. and Voss, F.D. 1998. Assessing Groundwater Vulnerability Using Logistic Regression. In Proceedings for the Source Water Assessment and Protection 98 Conference, Dallas, TX (Vol. 157165).

Thirumalaivasan, D.K. and Venugopal, M.K. 2003. AHP-DRASTIC: Software for specific aquifer vulnerability assessment using DRASTIC model and GIS, Environmental Modelling \& Software, 18: 645-656

U.S. Department of Agriculture, Natural Resources Conservation Service (USDA, NRCS). 2015.

U.S. EPA, 2012. http://water.epa.gov/drink/contaminants/basicinformation/ nitrate.cfm

Vias, J.M., Andreo, B., Perles, M.J. and Carrasco. F 2005. A comparative study of four schemes for groundwater vulnerability mapping in a diffuse flow carbonate aquifer under Mediterranean climatic conditions. Environ. Geol., 586-595.

Van Stempvoort, D., Lee, E. and Leonard, W. 1993. Aquifer Vulnerability Index (AVI): A GIS Compatible Method for Groundwater Vulnerability Mapping. Canadian Water Resources Journal, 25-37.

Wagenet, J.R., and Hutson, J.L. 1989. LEACHM: A Model for Simulating the Leaching and Chemistry of Solutes in the Plant Root Zone. Water Resources Institute, New York.

Webb, S.D. 1990. Historical biogeography. In R. L. Myers and J. J. Ewel (eds). Ecosystems of Florida, University of Central Florida Press, Orlando, Florida, pp. 70-102. 